Research Article

\title{
Development and Experimental Validation for Quantifying the Moisture Carryover in a Moisture Separator Using an Air/Water Test Facility
}

\author{
Kihwan Kim $\left(\mathbb{D}\right.$, Wooshik Kim $\left(\mathbb{D}\right.$, Jaebong Lee ${ }^{(D)}$, and Woo-Jin Jeon \\ Korea Atomic Energy Research Institute, Daedeok-daero 989-111, Yuseong-gu, Daejeon 34057, Republic of Korea \\ Correspondence should be addressed to Kihwan Kim; kihwankim@kaeri.re.kr
}

Received 10 February 2021; Accepted 16 July 2021; Published 26 July 2021

Academic Editor: Alexander Zulauf

Copyright (c) 2021 Kihwan Kim et al. This is an open access article distributed under the Creative Commons Attribution License, which permits unrestricted use, distribution, and reproduction in any medium, provided the original work is properly cited.

\begin{abstract}
The moisture carryover (MCO) of the primary separator in a steam generator is the most important design parameter to ensure high efficiency in a steam generator. There is an inherent limitation to experimentally evaluate the MCO under the prototype conditions. In this study, the air/water test facility was constructed based on the similarity law, and a new isokinetic system was developed to quantify the MCO. Several experiments were performed for the mass quality ranging from 0.315 to 0.382 . The accuracy and versatility of the experimental method was verified experimentally using a full and half scale of separators. The test results were compared with the prototype results. It was proved to be a reliable experimental method for evaluating the MCO of the moisture separator.
\end{abstract}

\section{Introduction}

The moisture separation system of a steam generator is composed of primary separators, a secondary separator (i.e., gravity region), and a steam dryer bank. It also plays an important role in ensuring the safety of turbines and a high efficiency in nuclear power plants. The performance of the system should satisfy the acceptable steam quality, namely, $0.1 \%$, under various operation conditions. The major parameter related to the criteria is the moisture carryover (MCO), which is defined as the moisture (i.e., droplet) amount contained in the steam flow. The majority of the droplets generated at the U-tube in a steam generator are removed in the primary separators. There are two representative types of a steam generator in Korea: a Combustion Engineering type and a Westinghouse type, as shown in Figure 1. Eventhough the type of the steam generator is the same, the moisture separator varies somewhat depending on the nuclear power plant's design power. The database of the MCO for various operating conditions in a steam generator is indispensable for designing the arrangement and overall efficiency of the moisture separator. However, there are not many data based on the actual operating condition. In addition, there is an inherent limitation in performing the test under the prototype condition because of a large cost. Therefore, many models based on the scaling law have been proposed over the past few decades. For the general types of pressurized water reactors (PWR), some steady-state air-water experiments were carried out to examine the effect of the superficial velocity of each phase and water level on the MCO using a reduced model. A detailed review of these experiments are given by the NUREG [1] report. Mauro et al. [2] summarized experimental efforts to develop the separator since 1977. Among them, Green and Hetsroni [3] investigated the MCO in air-water and steam-water test loops for practical applications. They quantified the MCO and compared them with that of the full-scale prototypical condition. They suggested a scaling law that the model should maintain the same superficial velocities in both phases. Sun [4] examined the MCO and the pressure drop for the reduced swirl vane model in a low pressure airwater loop. They analysed the experimental results for the flow rates and suggested a prediction model based on the 


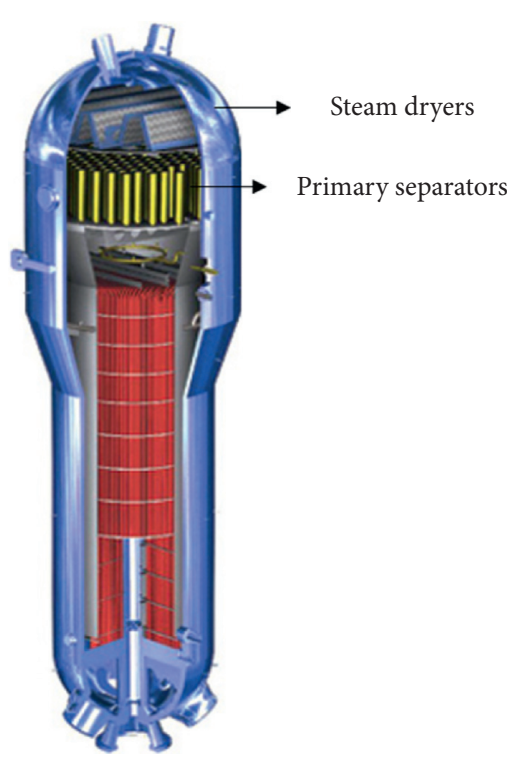

(a)



(b)

FIgURE 1: Steam generators in Korea nuclear power plants. (a) Combustion Engineering (CE) type. (b) Westinghouse (WH) type.

force balance equation. Recently, Liu and Bai [5] later carefully scrutinized the scaling law by theoretical and mathematical modelling. They improved the scaled model of Sun [4] and proposed the similarity criteria with a mathematical model. There are many factors that affect the MCO with hydraulic conditions such as the distribution of the small droplets [5], flow pattern [6], film thickness [7], phase concentration and swirl intensity [8], and so on. Katono et al. [9] focused on the two-phase flow characteristics and simulated the operating conditions by adjusting the quality and the twophase centrifugal force for boiling water reactors (BWR). They obtained almost the same results of the MCO compared with those of the conventional separator in a 1/2 scaled air-water test loop.

In the present study, an air/water test facility was constructed for the various types of conventional moisture separators in Korea. However, the experimental method should be validated with the prototype results because of the different working fluids. The density ratio of the working fluids was significantly different along the working pressure, and that induced the different pressure loss $[2,5]$. In addition, the maximum allowable liquid flow rate was limited due to the small momentum when the air and the water were mixed in a vertical separator [10]. From the previous research, there was not a representative method, but this research followed Katono et al.' [9] method and added the spray injection system, which is regarded as a conservative approach. The objective of this study was to validate the experimental method, which can be used to evaluate the MCO performance. There were not a large benchmark data from PWRs, but Kim [11] verified the MCO performance of the OPR1000 reactor in a full-scale steam-water test facility. The MCO of OPR1000 was quantified using two experimental set-ups consisting of different scales (half and full) under the same mass quality conditions. The obtained test results were compared with the available Kim et al.' [11] results to validate the experimental method.

\section{Experimental Test Facility}

2.1. Performance Evaluation of a Moisture Separator (PEMS) Test Facility. The performance evaluation of a moisture separator (PEMS) test facility was designed to assure the simulation of the flow fields of the moisture separator with a dryer inlet. The schematic diagram of the PEMS test facility, $12.4 \mathrm{~m}$ high, is shown in Figure 2.

The fluid system is composed of a test section, water reservoir, air supply system, water injection system, and mixing region. The geometry for the internal flow region and the dryer shape is preserved, and the size of the test section housing is determined considering the hydraulic diameter of the adjacent moisture separators. The test section is designed independently, and thus, it can be changed for various types of separators. The PEMS have two flow loops for the injection of air and water, which are driven by two blowers and a pump, respectively. The separated water from the test section is returned to the water reservoir, and the released two-phase mixture passing through the dryer outlet is vented to the atmosphere. The design pressure and temperature are $0.5 \mathrm{MPa}$ and $60^{\circ} \mathrm{C}$, respectively. The design specifications of PEMS are summarized in Table 1. The twophase mixture is generated in the mixing region by using 4 spray nozzles and air flows. The nozzles provide a water flow rate of $10 \mathrm{~kg} / \mathrm{s}$ with a supply pressure of $0.5 \mathrm{MPa}$. They reduce the size of the droplets, even at a low supply pressure, and achieve good mixing passing through the inlet pipe.

The system configuration, including instrumentation, is shown in Figure 3. The volumetric flow rate of air is measured by using a vortex flow meter, and the pressure and the temperature are measured simultaneously to calculate 


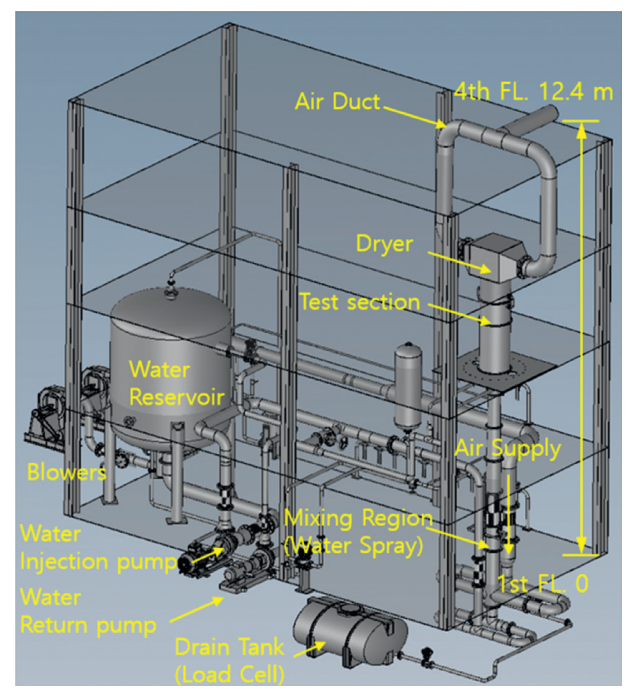

(a)

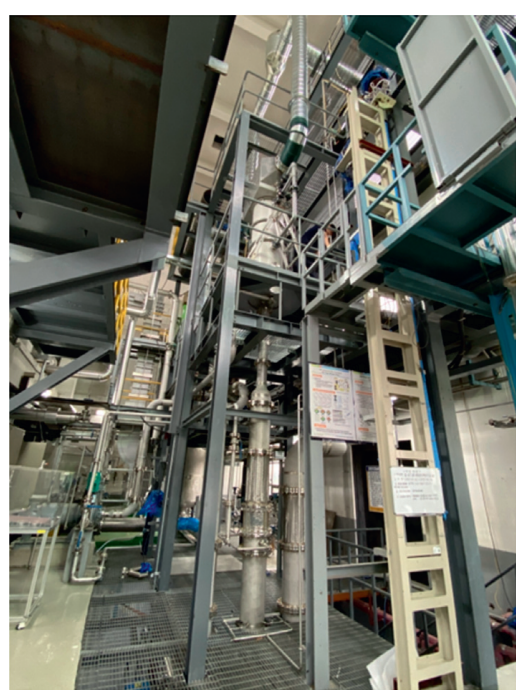

(b)

Figure 2: Schematic diagram of the PEMS test facility.

TABLE 1: Design specifications of PEMS.

Design pressure

Design temperature

Separator diameter

Separator height

Water mass flow rate

Air mass flow rate

\section{$0.5 \mathrm{MPa}$ \\ $60^{\circ} \mathrm{C}$}

$0.14-0.5 \mathrm{~m}$

$0.79-3.4 \mathrm{~m}$

Up to $36 \mathrm{~m}^{3} / \mathrm{hr}$ (ref. $1 \mathrm{~atm}$, head of $57 \mathrm{~m}$ )

Up to $7000 \mathrm{~m}^{3} / \mathrm{hr}$ (ref. $1 \mathrm{~atm}$, head of $1.2 \mathrm{kgf} / \mathrm{cm}^{2}$ ) the mass flow rate. The water flow rates are measured by means of the vortex and magnetic flow meters to cover the wide range of test conditions. The temperature, the differential pressure for the water level, and the pressure are measured along the main flow path. It is noted that, in this experiment, the highest grade instrumentation was applied to get more accurate results, and the accuracy is summarized in Table 2 . The sampling rate was $1 \mathrm{kHz}$, and the measured values were converted to the engineering unit. The experiments were carried out under a quasisteady state, and thus, the mass quality, void fraction, two-phase centrifugal force, and properties of the working fluids were calculated in real time and monitored in a human-machine interface (HMI) program.

2.2. Main Test Section. The full and half scale of moisture separators were tested to verify the experimental method. The half scale of the test section was linearly reduced at a scaling ratio of $1 / 2$ by referring to the prototype. As shown in Figure 4, the two-phase mixture was injected to the separator, and the break-up of droplets occurred by passing through the spinner blade. A swirl flow was generated, and the majority of the droplets were separated through the large number of holes on the surface. Finally, the entrained droplets driven by the gas flow were separated again due to the gravity and obstacles such as the wire mesh and cover plate. The instrumentation for the test section is shown in
Figure 5. The pressure, temperature, and differential pressure were measured from the inlet of the separator to the inlet of the dryer region to confirm the hydraulic test conditions during the experiment.

2.3. Measurement Method for Moisture Carryover. The moisture carryover at the dryer inlet is defined as follows:

$$
\operatorname{MCO}(\%)=\frac{\sum_{i=0}^{t} \overline{\dot{m}}_{f} \Delta t_{i}}{\sum_{i=0}^{t} \overline{\dot{m}}_{f} \Delta t_{i}+\sum_{t=0}^{t} \overline{\dot{m}}_{g}} \Delta t_{i} \times 100,
$$

where, $\overline{\dot{m}}_{f}, \overline{\dot{m}}_{g}$, and $\Delta t_{i}$ are the averaged liquid mass flow rate, gas liquid mass flow rate, and sampling time of measurement, respectively. The accurate measurement of the flow rate is indispensable to calculate the MCO under a steady-state condition. In addition, it is impossible to measure the flow rate of each phase simultaneously at the measurement point. Therefore, in this study, the isokinetic system was applied to the PEMS test facility, as shown in Figure 6. The isokinetic system is composed of an isokinetic nozzle, mass flow controller, scrubber system, and vacuum system, which makes the driving force by using the differential pressure between the test section and the vacuum chamber. The diameter of the isokinetic nozzle is a half inch from predicting the total mass of droplets considering the operating conditions. The stream line at the measurement point should be maintained during the sampling process to 


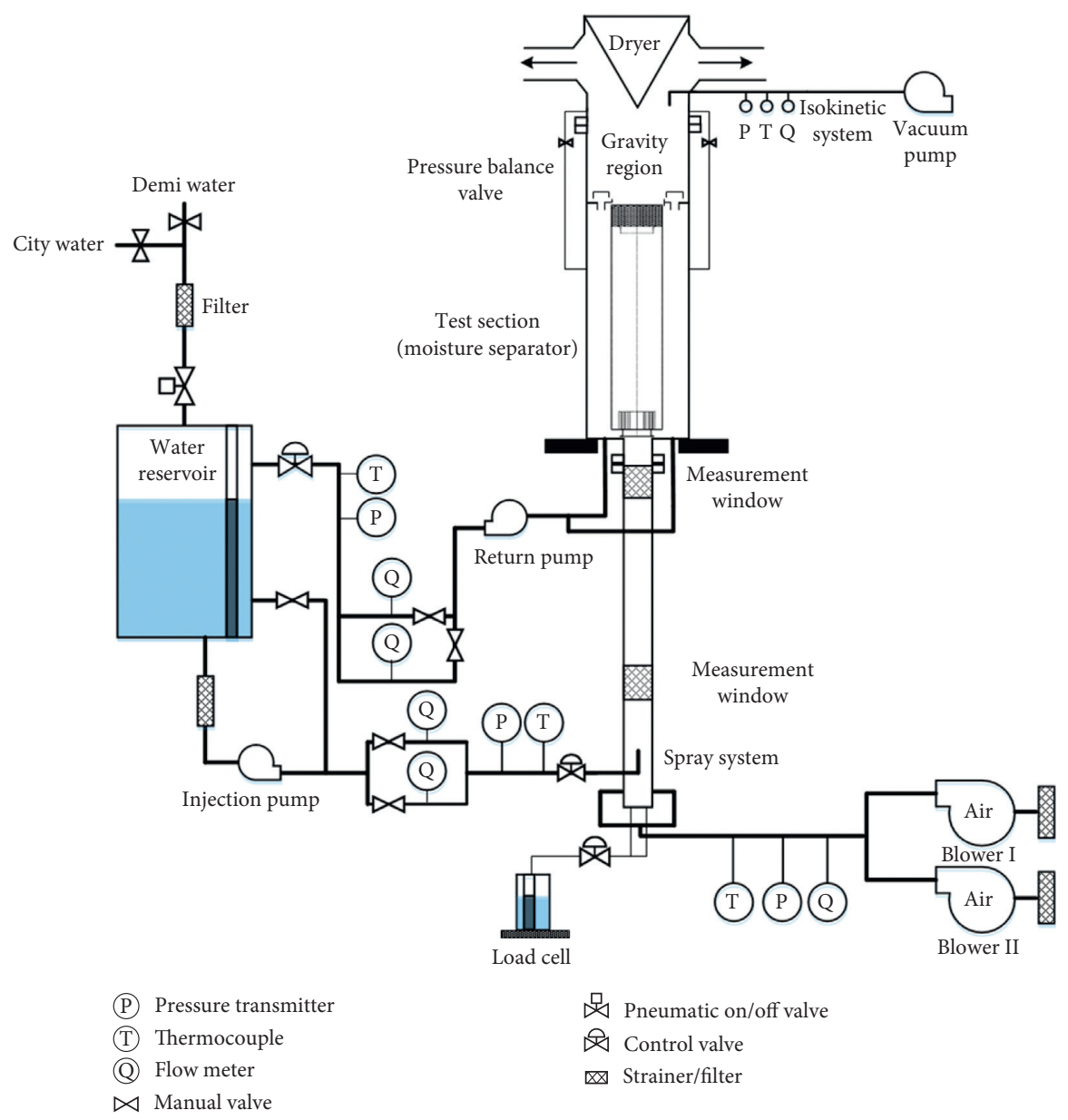

FIgURE 3: System configuration of the PEMS test facility.

TABLe 2: Accuracy of instrumentation.

\begin{tabular}{lcc}
\hline Instrumentation & Model & Accuracy \\
\hline Pressure transmitter & Rosemount 3051 & $\pm 0.15 \%$ of span \\
Differential pressure transmitter & Rosemount 3051 & $\pm 0.15 \%$ of span \\
Vortex flow meter & $8800 \mathrm{D}$ series & $\pm 1.00 \%$ of span (gas) \\
Magnetic flow meter & Panametrics & $\pm 0.51 \%$ of span \\
Mass flow controller & SLAMf51, BROOKS & $\pm 0.632 \%$ of span \\
Thermocouple & Watlow & $\pm 1.1^{\circ} \mathrm{C}$ or $0.4 \%$ \\
\hline
\end{tabular}

ensure the isokinetic system. Therefore, the velocity field was calculated from the mass balance equation, and the suction velocity was determined and controlled automatically by using the mass flow controller and vacuum pump. Before the measurement, the compressed air flows to the nozzle, whose aim is to remove any remaining droplets that may have induced an unexpected error. A two-phase mixture flows into the wet scrubber though the nozzle after the 3-way valve switching. The large droplets are removed by impinging the water in the wet scrubber. The small droplets may float in the scrubber tank, so there are two different types of hydrophobic porous filters that can remove the entrained droplets up to $0.45-40 \mu \mathrm{m}$ of diameter. Finally, the accumulated water in the scrubber tank can be measured by using the load cell, and the air flow rate is measured using the mass flow controller and can be integrated during the measurement. Therefore, the MCO can be predicted using equation (1).

\section{Moisture Carryover Test}

3.1. Test Condition. The PEMS test facility was designed and constructed based on the similarity law, which preserves the mass quality and the two-phase centrifugal force of the prototype test conditions. The mass quality and the twophase centrifugal force are defined in the following equations. 


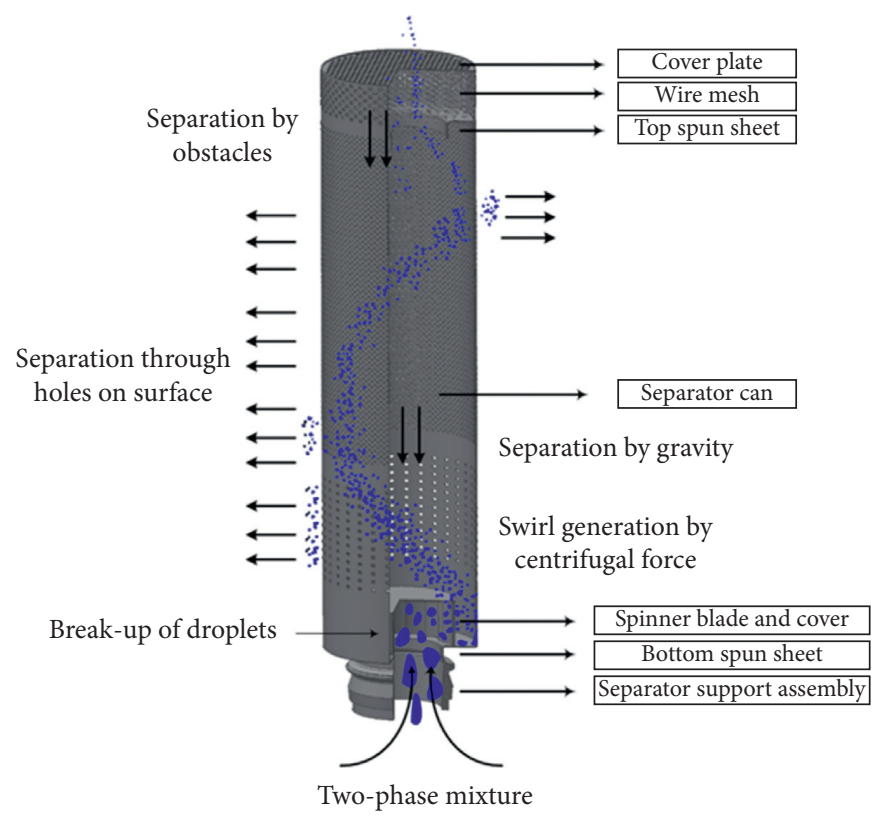

(a)

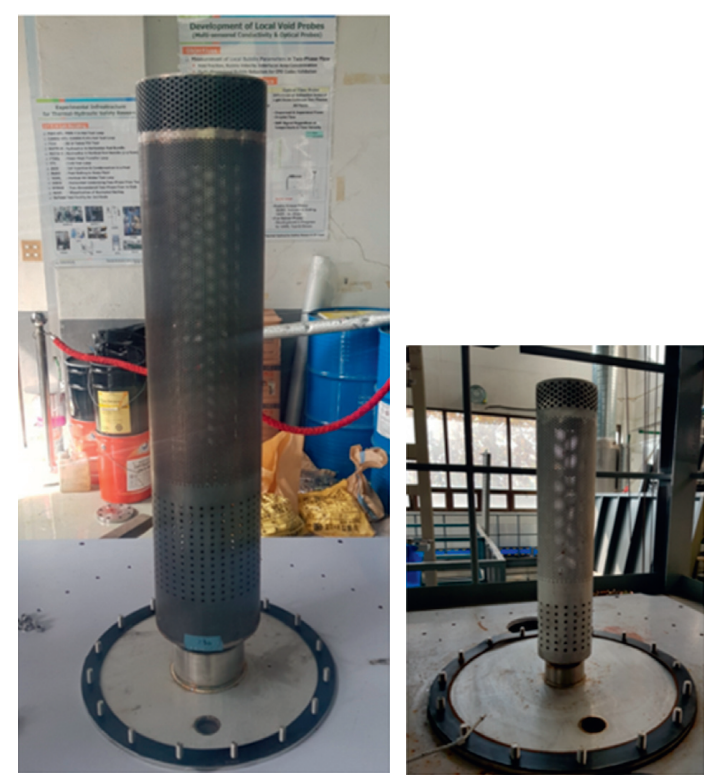

(b)

Figure 4: CE moisture separator. (a) Conceptual flow configuration. (b) Photograph of the test section.

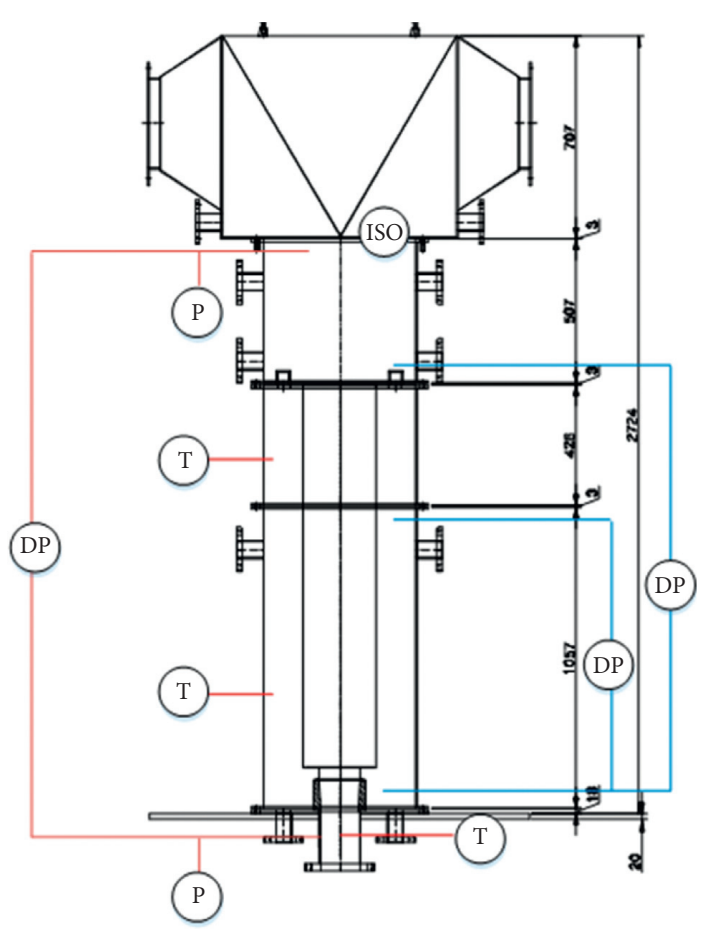

(a)

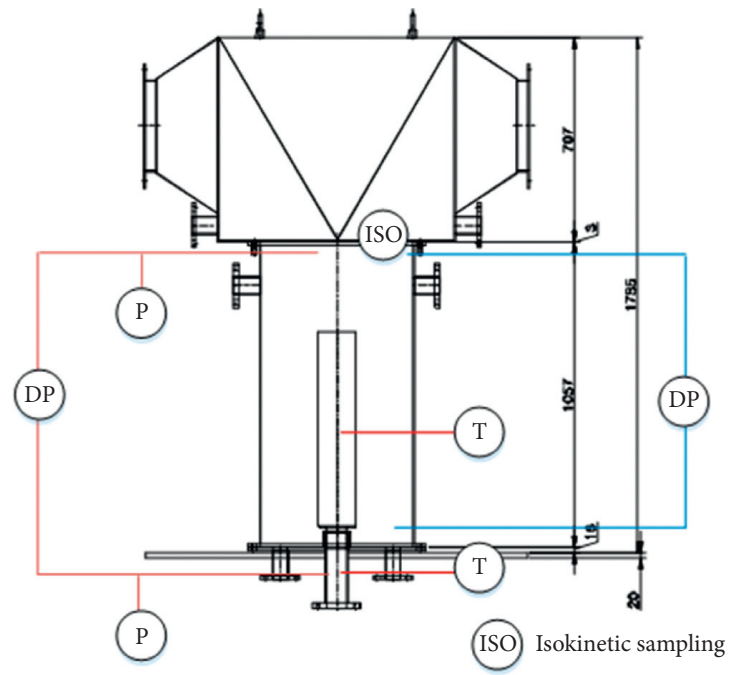

(b)

FIGURE 5: Instrumentation of the test section. (a) Full scale. (b) Half scale. 


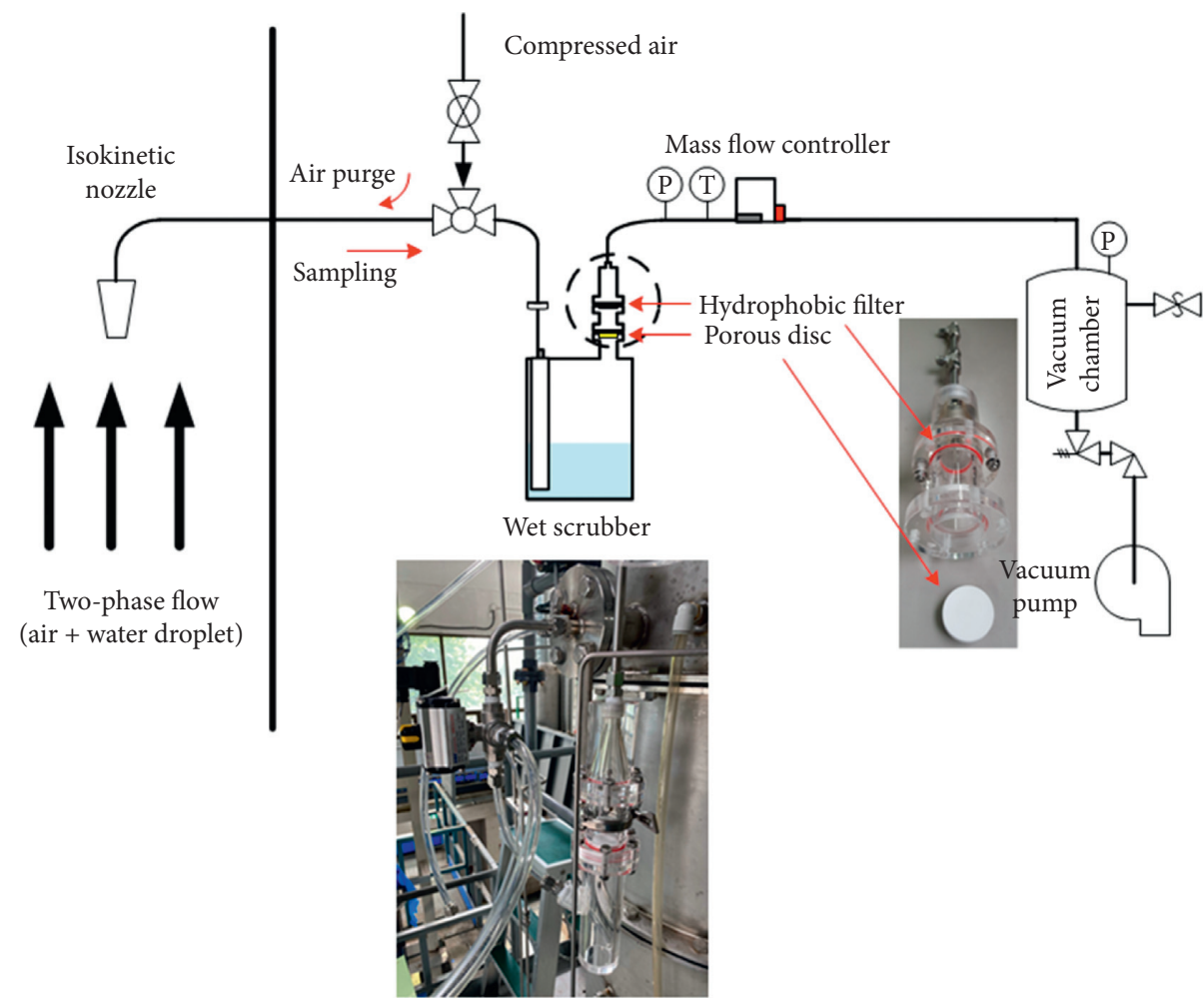

Do3 3-way valve SS Relief valve

\# Throttle relief valve Ball valve

$\triangle$ Angle valve

FIGURE 6: Schematic diagram and pictures of the isokinetic system.

$$
\begin{gathered}
x=\frac{\rho_{g} j_{g}}{\rho_{g} j_{g}+\rho_{l} j_{l}}, \\
F_{c}=\frac{\rho_{h}\left(j_{g}+j_{l}\right)^{2}}{D_{h, \mathrm{sp}} / 2},
\end{gathered}
$$

where $j_{g}, j_{l}$, and $D_{h, \mathrm{sp}}$ are the superficial velocities of the gas, liquid, and hydraulic diameter of the moisture separator, respectively. $\rho_{h}$ is the homogeneous density calculated from the density of each phase $\left(\rho_{g}, \rho_{l}\right)$ and the void fraction $(\alpha)$ as defined in the following equations.

$$
\begin{gathered}
\rho_{h}=\rho_{g} \alpha+(1-\alpha) \rho_{l}, \\
\alpha=\frac{x \rho_{l}}{x\left(\rho_{l}-\rho_{g}\right)+\rho_{g}} .
\end{gathered}
$$

The scaling law for the major dimensionless parameter of equations (2) and (3) can be expressed as

$$
\begin{gathered}
\frac{\left(F_{C}\right)_{p}}{\left(F_{C}\right)_{m}}=\frac{1}{1}, \\
\frac{(x)_{p}}{(x)_{m}}=\frac{1}{1},
\end{gathered}
$$

where the subscripts $m$ and $p$ denote the model and prototype. The independent variable of this experiment is the superficial velocity of each phase, so it can be derived from combining the above equations if we know the value of the prototype conditions as follows:

$$
\begin{aligned}
& j_{g, m}=\left[\left(\frac{D_{h, \mathrm{sp}} F_{c}}{2 \rho_{h}}\right)\left(\frac{x \rho_{l}}{x \rho_{g}+(1-x) \rho_{g}}\right)\right]_{p}, \\
& j_{l, m}=\left[\frac{1-x}{x} \frac{\rho_{g} j_{g}}{\rho_{l}}\right]_{p}
\end{aligned}
$$

In these experiments, three different tests having a mass quality range from 0.315 to 0.382 were performed for the full-scale and half-scale moisture separators, and the details of the scaling ratio and test conditions are summarized in Tables 3 and 4.

3.2. Experimental Results. The MCO was measured and evaluated for the full-scale and half-scale test sections with the same test conditions to verify the experimental method. All experiments were carried out under a steady-state controlling the hydraulic parameters. The measuring parameter is summarized as follows:

(1) Water injection flow rate

(2) Air injection flow rate 
TABLE 3: Summary of parameter scaling.

\begin{tabular}{lccc}
\hline Parameter & Prototype & Full scale & Half scale \\
\hline Design pressure $(\mathrm{MPa})$ & 7.5 & 0.1 & 0.1 \\
Design temperature $\left({ }^{\circ} \mathrm{C}\right)$ & 291 & 20 & 20 \\
Separator diameter ratio $\left(l_{R}\right)$ & 1 & $1 / 1$ & $1 / 2$ \\
Separator height ratio $\left(l_{R}\right)$ & 1 & $1 / 1$ & $1 / 2$ \\
Aspect ratio $(-)$ & 1 & $1 / 1$ & $1 / 1$ \\
Area ratio $\left(l_{R}^{2}\right)$ & 1 & $1 / 1$ & $1 / 4$ \\
Volume ratio $\left(l_{R}^{3}\right)$ & 1 & 831.9 & $1 / 8$ \\
Density ratio $\left(\rho_{l} / \rho_{g}\right)$ & 18.3 & $1 / 1$ & 831.9 \\
Quality $(-)$ & 1 & $1 / 1$ & $1 / 1$ \\
Centrifugal force $[1]$ & 1 & $1 / 1$ \\
\hline
\end{tabular}

TABLE 4: Test conditions for various qualities.

\begin{tabular}{lccc}
\hline Mass quality & 0.315 & 0.350 & 0.382 \\
\hline Operating pressure $(\mathrm{MPa})$ & & 0.101 & 20 \\
Operating temperature $\left({ }^{\circ} \mathrm{C}\right)$ & & 8885.2 & 11002.0 \\
Centrifugal force $\left(\mathrm{N} / \mathrm{m}^{3}\right)$ & 7352.5 & $19.2 / 13.6$ & $22.4 / 15.8$ \\
$j_{g}(\mathrm{~m} / \mathrm{s})($ full/half $)$ & $16.9 / 11.7$ & $0.043 / 0.031$ & $0.043 / 0.031$ \\
$j_{l}(\mathrm{~m} / \mathrm{s})$ (full/half) & $0.043 / 0.031$ & \\
\hline
\end{tabular}

TABle 5: Statistical values of the hydraulic parameters.

\begin{tabular}{|c|c|c|c|c|c|c|c|}
\hline \multirow{2}{*}{\multicolumn{2}{|c|}{ Test section/quality }} & \multicolumn{2}{|c|}{0.315} & \multicolumn{2}{|c|}{0.350} & \multicolumn{2}{|c|}{0.382} \\
\hline & & AVG & C.V & AVG & C.V & AVG & C.V \\
\hline \multirow{4}{*}{ Full scale } & Pressure (MPa) & 108.75 & 0.06 & 110.49 & 0.05 & 113.33 & 0.04 \\
\hline & Temperature $\left({ }^{\circ} \mathrm{C}\right)$ & 25.5 & 0.32 & 26.3 & 0.41 & 26.6 & 0.20 \\
\hline & $j_{g}(\mathrm{~m} / \mathrm{s})$ & 16.13 & 0.31 & 18.49 & 0.22 & 21.53 & 0.29 \\
\hline & $j_{l}(\mathrm{~m} / \mathrm{s})$ & 0.04 & 0.47 & 0.04 & 0.54 & 0.04 & 0.62 \\
\hline \multirow{4}{*}{ Half scale } & Pressure (MPa) & 103.65 & 0.03 & 104.42 & 0.03 & 106.04 & 0.03 \\
\hline & Temperature $\left({ }^{\circ} \mathrm{C}\right)$ & 13.2 & 0.24 & 14.3 & 0.43 & 13.2 & 0.83 \\
\hline & $j_{g}(\mathrm{~m} / \mathrm{s})$ & 11.33 & 1.00 & 13.32 & 0.97 & 15.40 & 0.81 \\
\hline & $j_{l}(\mathrm{~m} / \mathrm{s})$ & 0.03 & 0.26 & 0.03 & 0.26 & 0.03 & 0.25 \\
\hline
\end{tabular}

(3) Pressure and temperature from the separator inlet to the outlet

(4) Accumulated water of the scrubber tank

(5) Pressure, temperature, and air flow rate of the isokinetic nozzle

The criteria of the allowable data scatters were confirmed from the coefficient of variation to evaluate the validity of the measuring parameters. The coefficient of variation reveals the ratio of the averaged value and the standard deviation, as shown in the following equation.

$$
\text { C.V }(\%)=\frac{\sigma_{\text {STD. }}}{\bar{X}_{\mathrm{AVG}}} \times 100
$$

The inlet pressure, temperature, and flow rate of each phase were maintained within $\pm 1.0 \%$ of the C.V to operate in a steady-state condition. The major independent parameters were the injected water and air flow rates, but the mass quality and two-phase centrifugal force should coincide with the prototype conditions. The system pressure was determined by the total flow rates of the two-phase mixture, so the properties of working fluids such as the density, viscosity, and surface tension changed according to the test conditions. Therefore, the quality and two-phase centrifugal force were calculated in real time, and the hydraulic parameters were adjusted simultaneously to satisfy the requirements. The statistical measured values and test results are summarized in Tables 5 and 6, respectively. The steady-state conditions were well maintained, and the mass quality and two-phase centrifugal force showed good agreement with the prototype conditions. Therefore, it was safe to say that these experiments yielded reliable results with the test conditions.

As mentioned earlier, a single moisture separator was simulated in this study. Thus, the flow region was restricted by the housing structure. In actuality, the separators were located vertically on a deck that had a large flow path and 
TABle 6: Comparison of the major flow conditions with the prototype.

\begin{tabular}{ccccc}
\hline \multicolumn{2}{c}{ Test section/mass quality } & 0.315 & 0.350 & 0.382 \\
\hline \multirow{4}{*}{ Full scale } & Quality (-) & 0.315 & 0.349 & 0.385 \\
& Relative error (\%) & -0.16 & -0.29 & 0.78 \\
& Centrifugal force $\left(\mathrm{N} / \mathrm{m}^{3}\right)$ & 7358.4 & 8812.3 & 11102.7 \\
& Relative error (\%) & 0.08 & -0.82 & 0.92 \\
Half scale & Quality (-) & 0.313 & 0.351 & 0.383 \\
& Relative error (\%) & -0.63 & 0.14 & 0.13 \\
& Centrifugal force (N/m ${ }^{3}$ ) & 7254.7 & 8871.8 & 11205.9 \\
& Relative error (\%) & -1.33 & -0.15 & 1.85 \\
\hline
\end{tabular}

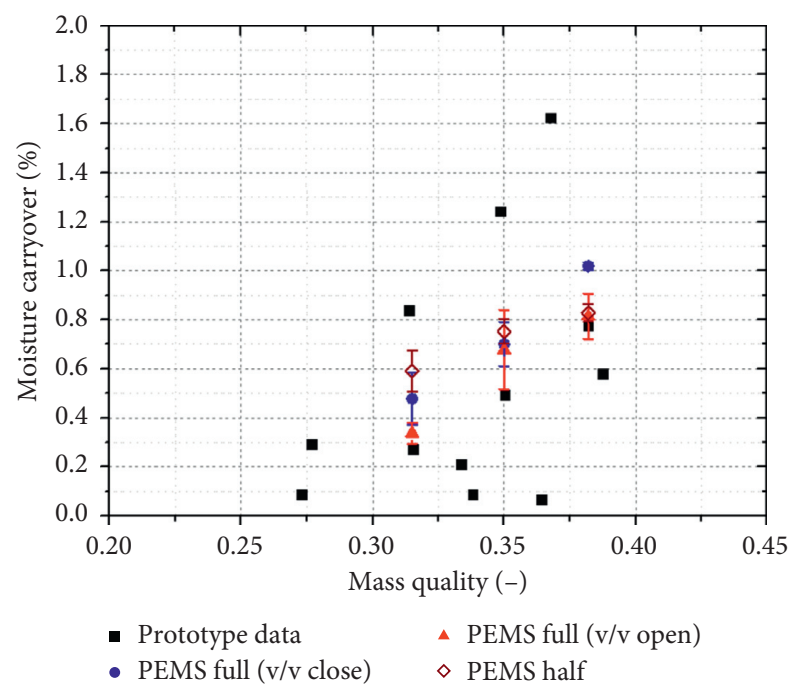

FIGURE 7: Comparison of moisture carryover along the quality.

opening space, i.e., the gravity region, though there were a number of separators in the steam generator. The pressure field of the PEMS test section may have been different than that of the prototype, so the pressure balance valves were set up between the housing and gravity regions. Therefore, additional sensitivity tests were performed to clarify the effect, and the MCO was compared as in Figure 7. As the two-phase mixture discharged continuously from the surface flow holes on the separator, a vortex was generated in the housing. The water was centrifuged to the housing wall, and it flowed downward due to the large density, but the air moved up to the top region. The droplets entrained by the air may have contributed to the increase of the MCO. For this reason, the MCO was slightly overestimated, as shown in Figure 8, when the valve was closed. On the other hand, the separated droplets did not affect the MCO when the pressure valve was opened, and it was regarded as a realistic prediction of the MCO. The results were also compared with those of the half-scale test section. The overall trend of MCO was characterized by the mass quality, and the MCO was close to those of the full-scale results. The MCO of half scale was slightly overestimated for the low quality case, but the results were placed within the uncertainty range of prototype data. Although it was very difficult to simulate exactly the complex two-phase flow separation mechanism, the results

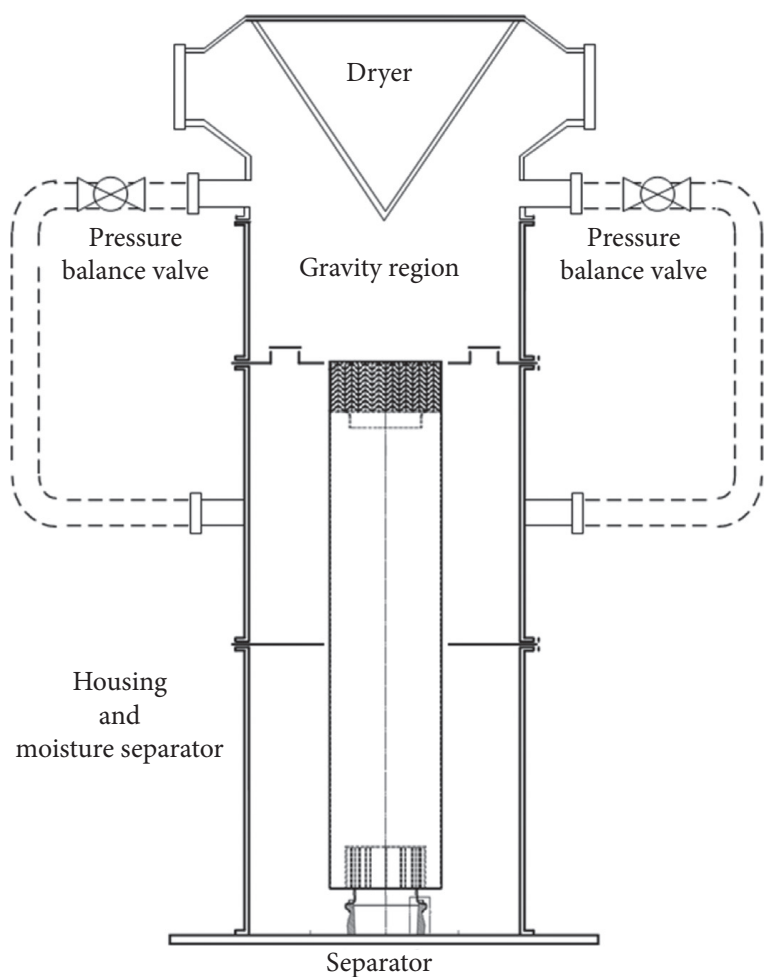

Figure 8: Schematic diagram of the pressure balance valve.

of MCO were in fair agreement with each other by using the PEMS test facility.

\section{Conclusion}

An air/water test facility called the PEMS was designed based on the similarity law and constructed to measure the MCO for various types of separators. The steam/water conditions of the prototype were converted to the air/water conditions preserving the mass quality and two-phase centrifugal force. The CE moisture separators that had a full-scale and halfscale were tested to verify the experimental method by comparing the prototype. The air/water tests were performed for various mass qualities ranging from 0.315 to 0.382 under a steady-state condition. The test conditions were strictly satisfied by maintaining the steady-state condition, and the MCO was accurately quantified through a highly reliable isokinetic system developed to measure the flow rate of each phase individually. All of the test results showed good agreement with those of the prototype within an uncertainty range. In this study, the experimental method showed reliable and versatile results and its usefulness in predicting the MCO of a moisture separator.

\section{Data Availability}

The data used to support the findings of this study are available from the corresponding author upon request.

\section{Conflicts of Interest}

The authors declare that there are no conflicts of interest. 


\section{Acknowledgments}

This work was supported by the Korea Institute of Energy Technology Evaluation and Planning (KETEP) grant funded by the Korean Government (MOTIE) (20181510102390) (Localization of Westinghouse Steam Generator Submerged Separator).

\section{References}

[1] C. Y. Paik, G. Mullen, C. Knoess, and P. Griffith, "Steam separator modelling for various nuclear reactor transients," Nuclear Engineering and Design, vol. 108, no. 1-2, pp. 83-97, 1988.

[2] G. Mauro, M. Sala, and G. Hetsroni, "Improved Italian moisture separators (IIMS)," Nuclear Engineering and Design, vol. 118 , no. 2, pp. 179-192, 1990.

[3] S. J. Green and G. Hetsroni, "PWR steam generators," International Journal of Multiphase Flow, vol. 21, pp. 1-97, 1995.

[4] F. T. Sun, "The investigation on performance of steam generator stationary vane separator," Chinese Journal of Nuclear Science and Engineering, vol. 15, no. 3, pp. 213-219, 1994.

[5] L. Liu and B. Bai, "Scaling laws for gas-liquid flow in swirl vane separators," Nuclear Engineering and Design, vol. 298, pp. 229-239, 2016.

[6] Z. Xiong, M. Lu, M. Wang, H. Gu, and X. Cheng, "Study on flow pattern and separation performance of air-water swirlvane separator," Annals of Nuclear Energy, vol. 63, pp. 138-145, 2014.

[7] H. Funahashi, K. Hayashi, S. Hosokawa, and A. Tomiyama, "Study on two-phase swirling flows in a gas-liquid separator with three pick-off rings," Nuclear Engineering and Design, vol. 308, no. 3, pp. 205-213, 2016.

[8] S. Liu, L.-L. Yang, D. Zhang, and J.-Y. Xu, "Separation characteristics of the gas and liquid phases in a vane-type swirling flow field," International Journal of Multiphase Flow, vol. 107, pp. 131-145, 2018.

[9] K. Katono, N. Ishida, T. Sumikawa, and K. Yasuda, “Air-water downscaled experiments and three-dimensional two-phase flow simulations of improved steam separator for boiling water reactor," Nuclear Engineering and Design, vol. 278, pp. 465-471, 2014.

[10] G. B. Wallis, One-Dimensional Two-Phase Flow, McGrawHill, New York, NY, USA, 1969.

[11] J. I. Kim, M. Y. Kim, H. S. Bae, and B. E. Lee, "An experimental investigation for the moisture separation system of a steam generator for nuclear power generation," in Proceedings of International Congress on Advances in Nuclear Power Plants (ICAPP), Reno, NV, USA, June 2006. 